\title{
A Tale of Two Programs: Broadening Participation of Underrepresented Students in STEM at Loyola Marymount University
}

\author{
David Berube ${ }^{1}$, Christina Eubanks-Turner, Edward Mosteig, Thomas Zachariah \\ Loyola Marymount University, USA
}

\begin{abstract}
This paper highlights two programs that successfully support underrepresented students in STEM disciplines at Loyola Marymount University (LMU). ACCESS (A Community Committed to Excellence in Scientific Scholarship) is a program that focuses on academics and critical thinking skills, which provides a threeweek residential component for incoming students and continued mentoring during their first year in college. The LMU McNair Scholars Program is one of over 150 McNair Scholars Program sites federally-funded by the U.S. Department of Education and has the overarching goal of increasing number of graduate degrees awarded to students from underrepresented segments of society. For both ACCESS and McNair, we give an overview of each program and detail about components of the programs that have led to success. In addition, we specifically address the rewards and challenges when providing mentorship at multiple levels.
\end{abstract}

Keywords: Underrepresented students, mentoring, broadening participation, undergraduate research, first-generation students

\section{Introduction}

A number of studies have focused on the pipeline into the sciences, as well as factors related to attrition and persistence of students from traditionally underrepresented groups in STEM fields (NAP, 2011; Chubin et al. 2009; Herzig, 2004). Some research suggests that non-cognitive or social-psychological factors impact selection of and persistence in STEM majors along with other demographic factors, particularly for students from underrepresented groups, that is, students of color, first-generation, and low-income students. The first year of college is critical to student success because it sets the stage for the remaining undergraduate experiences (Nora, 2001). Furthermore, underrepresented students may experience differing racial dynamics within college environments (Chang et al., 2006; Steele and Aronson, 1998). Chang et al. (2006) found that Black students at predominantly white dominant institutions often feel anxiety and fear at being the only one or one of a few African Americans in a particular environment. This anxiety can lead African Americans to seek support through increased contact with other African Americans. The first level of help students use is their peers, and students may be without an appropriate peer community due to a lack of critical mass. Research on school cultures has identified school belonging or connectedness as an important factor in students' achievement motivation (Anderman \& Freeman, 2004). Students need to feel that they are cared about and meaningfully connected to a group; lack of such a sense of belonging has been linked with dropout (Ianni \& Orr, 1996). Tinto (1997) studied the influence of a learning community on student persistence and determined that a small support community of peers can have a positive effect on students.

\footnotetext{
${ }^{1}$ Seaver College of Science and Engineering, Seaver Science Hall 104, Los Angeles, CA, USA, E-mail: dberube@lmu.edu

Berube, D., Eubanks-Turner, C., Mosteig, E., \& Zachariah, T. (2018). A tale of two programs: Broadening participation of underrepresented students in STEM at Loyola Marymount University, Journal of Research in STEM Education, 4(1), 13-22.
} 
Individuals with high self-efficacy have been shown to exert more effort in the face of difficulty and to persist longer. Huang et al. (2000) found that high self-confidence and high aspirations for degree attainment were significant in predicting degree completion. Furthermore, high self-confidence and degree aspiration decreased the effect of family financial support and level of parental education on degree completion (Huang et al., 2000).

In this article we feature two programs that have been successful at supporting students from underrepresented groups at Loyola Marymount University (LMU): The ACCESS (A Community Committed to Excellence in Scientific Scholarship) program, which is a program for underrepresented first-year STEM majors who enter LMU's College of Science and Engineering and the LMU McNair Scholars Program, which is a mentoring program for continuing LMU students who are underrepresented in STEM. We will give pertinent background about these programs and discuss components of both programs that have led to successful implementation. We will also mention evidence of successes in each of the programs.

\section{The ACCESS Program}

The ACCESS program is a year-long experience for first-year students in the Seaver College of Science and Engineering at LMU. Selected students participate in an intense three-week summer program before the beginning of the fall semester and receive continued advising and mentoring throughout their freshman year at LMU. The program aims to prepare students for academic excellence through collaborative engagement in scientific scholarship. Through participation in the summer program and activities throughout their freshman year, ACCESS students live by the program motto "You are no longer responsible solely for your own success, but for the success of your peers as well.'

The intent is to help students (1) increase confidence in math and science, (2) increase college preparedness and a sense of belonging, (3) demonstrate pro-social skills in scientific scholarship, and (4) remain and (5) excel in the sciences and potential ways to better support students throughout the college year in hopes of encouraging them to persist in STEM careers.

The goals and objectives of ACCESS include the following:

- $95 \%$ of ACCESS Scholars will be retained into their sophomore year

- ACCESS Scholars will achieve an overall first term GPA of 3.2 or higher

- $50 \%$ of ACCESS Scholars will participate in funded research opportunities during their time at LMU

- $85 \%$ of ACCESS Scholars will complete a bachelor's degree in a STEM discipline

- $60 \%$ of ACCESS Scholars will apply to graduate or health professions programs upon graduation, and the remainder of those who graduate will immediately enter the STEM workforce

Each year, a summer community-committed transition program enrolls 18 incoming freshman students who are from low socio-economic backgrounds and are often either first-generation college students or under-represented minorities in the sciences. We invite approximately 50 to 100 students from the incoming class of the college of science and engineering to apply to the program. Each student invited to apply must be of low socio-economic status. Of these 50 to 100 students, about 35-40 apply to the program. One-on-one interviews are conducted with all applicants and 18 participants each year are selected to participate.

\section{Components of the ACCESS program}

Each activity in the ACCESS Summer Program has been carefully designed to meet the program goals. Activities fall into one or more of the following areas: academic and professional development, personal development, and community building. 


\section{Academic and professional development activities}

The academic activities of the summer program reflect the diversity in majors of the program participants. However, we focus on two main areas: communication skills and mathematical modeling. The art of and skills necessary for communication are integral to any discipline. We offer learning experiences that result in the students becoming well-versed in communicating their ideas orally and through writing. Virtually all the academic activities culminate with individual or group presentations or written papers. ACCESS is focused on mathematical modeling because the ability to analyze data, identify trends, and draw conclusions are crucial skills needed in any discipline, and most students do not have any experience in these areas before entering college.

\section{Personal development}

We have two main activities aimed at having the students reflect on who they are and want to be. The first activity is a two-part reflection exercise. In the first part, the students are asked to reflect on their current lives (good and bad habits, things they would like to improve about themselves, things they want to learn in the short and long term, etc.) and their ideal future. In the second part, the students are asked to write about concrete goals (academic, personal, and social). They write about the things they need to do each day, month, and year to achieve those goals. The students really enjoy this exercise, and many of them remark that they never actually sat down to think about what kind of person they want to be over the long term. Studies have also shown that setting, elaborating, and reflecting on personal goals improves academic performance (Morisano et al. 2010).

The students also have one "day of service" during the three-week summer program. On that day, we visit Homeboy Industries in downtown Los Angeles to see how former gang members turn their lives around to become productive members of society. We then walk through Skid Row in downtown Los Angeles to The Midnight Mission, where the students prepare and serve dinner to hundreds of homeless people.

\section{Community building}

Perhaps the most important aspect of the ACCESS summer program is the formation of a tightly-knit community of scholars who are dedicated to one another's success. A key to retaining students during and beyond their freshman year is to instill in them a sense of belonging at the University. Over the course of the three weeks, the students engage in a variety of activities meant to make them feel at home with one another, with the LMU campus, and in the city of Los Angeles. These include fields trips (Santa Monica Pier, Dodger game, bowling, museums, etc.), scavenger hunts on campus, shared meals, and soccer games.

Overall, the program provides an opportunity for freshman to participate in an all-expense paid, three-week residential program that focuses on academics and critical thinking in the sciences. Students are introduced to key faculty, staff, and administrators before the first day of classes and are engaged with scientific projects that encourage them to work collaboratively. Students also produce technical reports of their work and give formal presentations to a variety of audiences during the program.

\section{The Ronald E. McNair Program at LMU}

In general, McNair programs have a general philosophy of creating a community of academic excellence that provides intense experiences through research and faculty mentoring to help students find their passion and prepare them for graduate school, where all of our scholars are either first-generation and low-income students or from underrepresented groups in STEM fields. The goals of the McNair program are for the scholars to possess the knowledge, ambition and confidence to pursue and complete the doctoral career path, carry out research and other scholarly activities, communicate effectively, possess leadership skills, and exhibit prosocial skills in an academic setting.

The McNair Scholars Program at LMU was designed to sustain a cohesive support system for firstgeneration, low-income and underrepresented participants. LMU's local enrollment area encompasses the 
densely-populated urban metropolis of Los Angeles, where public high schools and one of the largest community college systems in the country serve a significant population of first-generation, low-income students. Within this population there are many students classified as high-achieving, but who are underrepresented in both STEM fields and Ph.D. programs. According to data collected from a series of interviews conducted with LMU faculty in the 2011- 2012 academic year, the LMU target population of participants in LMU's McNair Scholars Program experience specific academic, social, financial, and other challenges.

During the McNair selection process, we focus on students who have some interest in research, but also accept students who may be undecided in terms of their long-term objectives. Our goal is to help such students overcome anxiety, self-doubt, and familial pressure to enter the work force immediately upon graduation. We often encountered first-generation college students whose families thought that graduate school was a foolish choice, and we work directly with those families to help them better understand the graduate school process and the career options that would become possible with post-baccalaureate studies. Academic and social challenges encountered by first generation, low-income, and underrepresented students are often reinforced by financial hardships, which are particularly pronounced at LMU because of the high cost of tuition. In particular, many of these students often feel responsible for taking care of other family members and have minimum wage jobs to provide financial assistance to their families. Being able to afford LMU's tuition is a constant concern, leaving the students feeling more isolated, and set up for failure. This is particularly problematic for students starting at an academic disadvantage, who are more likely to need an extra year to graduate due to the sequential nature of the courses in STEM disciplines.

\section{The LMU McNair Program Components}

The LMU McNair Program offers scholars rigorous research experiences including an on-campus summer research program, guidance and strong support to secure off-campus research and internship opportunities, faculty mentoring, guidance and financial support for research projects during the academic year, support and encouragement for McNair Scholars and alumni to attend and present their work at academic and professional conferences.

\section{Undergraduate Research Experience}

The Program provides high quality research experiences for LMU McNair Scholars by integrating them into the LMU undergraduate research environment in several ways. The director of the program invites all newly-selected McNair scholars before their junior year to participate in an existing LMU summer research program. In the fall of their junior year, scholars join the research teams of LMU McNair Research Advisors. Mentoring and guidance by the McNair Team ensures that McNair Scholars have a summer research opportunity after their junior year, either at LMU or in an off-campus program.

In addition to these activities, all McNair students participate in at least two LMU Undergraduate Research Symposia during junior and senior year. Scholars also travel with Faculty Mentors and Research Advisors to academic regional and national conferences in their field and are responsible for reporting to their fellow McNair Scholars on their experiences. Through all of these activities, McNair Scholars learn to give and receive helpful feedback to develop the necessary confidence and public speaking skills for success on the road to the Ph.D.

\section{Research Advisors and McNair Mentors}

After consultation with the scholars, the McNair Team matches students with qualified LMU Research Advisors who have proven records of success in fostering the research excellence of talented first-generation and underrepresented students. Multiple LMU faculty, who serve as Research Advisors, are first in their family to attend college and are underrepresented minorities in STEM. Research Advisors facilitate the engagement of McNair Scholars in a research project suitable for presentation at venues such as the Southern California Conference for Undergraduate Research (SCCUR), Society for the Advancement of Chicanos and Native 
Americans in Science (SACNAS), National Society for Black Engineers (NSBE), Society of Women Engineers (SWE), and at discipline-specific conferences. Research Advisors ensure that the scholars disseminate their findings in the form of a paper or a poster, with the intent of submitting it to a peer-reviewed journal. These activities introduce scholars to the procedures involved in scientific inquiry and the importance of academic research, thereby motivating them pursue graduate education in STEM.

To ensure scholars receive adequate mentoring, the director of the McNair program assigns a full-time LMU faculty member as a mentor to each of the scholars admitted to the program. Faculty Mentors meet with the scholars at least once a month and monitor their progress in achieving short-term and intermediate goals using various measures and report back to the director regularly. LMU has a significant number of faculty members from groups traditionally underrepresented in STEM fields, including women, underrepresented minorities and individuals who are the first in their family to attend college, and former McNair Scholars. Faculty Mentors periodically attend student academic presentations that take place during the McNair class and provide helpful feedback to students regarding the quality of their work and presentation styles. Assigned Faculty Mentors and Research Advisors work with students to create their initial research question. They also coach students in the designing, implementing, analyzing, writing and presenting of their research papers throughout the academic year. When possible, mentors also assist students in publishing their research sometimes as co-authors. One of the most critical roles that faculty mentors play is that of introducing and recommending McNair Scholars to their national network and advocating on behalf of their mentee for coveted graduate school slots and fellowships. Since 2012, approximately 56 LMU faculty members (20 from the Bellarmine College of Liberal Arts and 36 form the Seaver College of Science and Engineering) have contributed to the program as mentors, research advisors, and/or summer faculty associates.

\section{Success and Challenges}

\section{Advantages of Faculty Driven Programs}

Both the ACCESS Program and the McNair Scholars Program are faculty-driven, which adds to their strength. Each program is directed by faculty members, which brings about a host of challenges and advantages. Because each program has a director overseeing all components, the workload is very demanding. For the ACCESS program, the director must coordinate items ranging from food and housing to curriculum development, teaching, and mentoring.

For the McNair Scholars Program, the advantages of a faculty-driven program are manifold. Due to their background and first-hand experience, faculty are in a unique position to mentor students as they navigate through the graduate admission process. Since faculty had previously gone through the same process as the scholars, they are able to provide guidance and feedback that comes from direct experience. In addition, the faculty are often part of a closely knit group of academic researchers. During the application process, students are often given the opportunity to connect directly into that network through introductions made by their faculty mentors.

When a McNair site is faculty driven, students are able to see how the faculty member engages in research herself or himself. Such faculty members often have direct knowledge of other researchers on campus whose research closely aligns with the interests of their scholars. Moreover, since faculty members frequently deliver presentations at conferences, they are also capable of providing guidance for the scholars who are about to head off and give their own research presentations for the first time.

\section{Individualized Care}

One of the primary advantages of hosting programs like McNair and ACCESS at LMU is the comparatively small size of the institution. It is much easier for faculty and staff to gain an understanding of the landscape of the university and interact with multiple segments at both administrative and academic levels. This allows faculty and staff to support students in an individualized manner. Regardless of whether a student 
is excelling or struggling, most faculty are aware of various sources of support and can draw upon multiple people to work directly with the student. This helps to provide students with targeted support that addresses their immediate needs. Specifically, for the McNair program, whenever a student is seeking opportunities to promote his or her success, it is fairly common for a faculty mentor to initiate contact with the student and hold conversations with other faculty members that ultimately lead to a network of mentors. As a case in point, it is not uncommon for faculty to help students identify research opportunities on campus while simultaneously replacing off-campus minimum wage jobs with meaningful work on campus such as grading or tutoring.

The smaller size of the university can also lead to the development of intersecting, supportive communities. Most faculty in the College of Science and Engineering at LMU are aware of both the ACCESS and McNair program, and, often, when they learn about one of our scholars facing specific challenges, they will pick up the phone or send an email in order to begin a dialog about how to best support that student. This sense of community makes it much easier to strengthen certain aspects of both programs. Faculty regularly come to events showcasing our scholars' research, and they often provide valuable feedback. In turn, students come to recognize a good number of these faculty members as allies. From the student perspective, this expands the network of individuals that can provide both tangible and emotional support.

\section{Community Building}

As previously mentioned, community is an very important aspect of the success of the scholars in the ACCESS program. At the end of the summer portion of the program, the students have bonded socially and academically. Consequently, at the start of their first semester in college, they feel like they belong at the university not just because they have a built-in group of friends, but also because those friends understand how to navigate the university. When these scholars encounter either academic or general life challenges, which are typically experienced by all first-year undergraduates, they not only turn to their individual families for encouragement, but also recognize the value of the support network provided by ACCESS. If a student in the program is giving a presentation on campus, for example, the ACCESS faculty leaders and other ACCESS scholars will often attend to demonstrate their support.

In the McNair program community is fostered in a myriad of ways. Throughout students' time in McNair they engage consistently with their peers in their specific cohort as well as their peers in other cohorts. One way community is built is through the one-credit-hour seminar classes scholars attend during the academic year where they discuss topics that include successful study habits, preparing and planning for undergraduate research, preparing for the GRE and applying to graduate school. A unique feature of the LMU McNair Scholars program is the summer seminars for scholars. Each summer a scholar participates in McNair they attend seminars to help "fine tune" their research presentations. During these sessions faculty from various fields and other McNair scholars listen to scholars' research presentations and critique their presentations. As scholars present multiple times throughout the summer, scholars adapt and improve their presentations based on faculty and peer input. This helps to further acclimate scholars into the academic community and give targeted professional development, which many scholars have noted as invaluable.

Another unique feature of the LMU McNair Program is its deliberate, multi-pronged engagement with scholars' families, as the project team believes familial support is crucial in ensuring scholars' academic success. At regular McNair events, including an annual banquet, the program celebrates the scholars' accomplishments, and engages their families in discussions about their children's academic progress, graduate school plans, and their trajectory to the doctoral degree.

A common goal to both programs is the promotion of self-efficacy in participants. In the ACCESS program self-efficacy and student confidence is promoted as soon as students step foot on campus. In particular, as soon as students enter the program one of their initial exercises is to have them describe themselves as scientists ten years in the future, and then share their story in multiple contexts: once with an assigned partner who is instructed to engage with an attentive ear and ask questions, and another time with the entire cohort 
of 18 students. Similarly, with McNair, we have students give multiple presentations to their peers and a select group of faculty members. Those presentations often take the form of polished research talks, which helps the scholars build confidence. The presentations are sometimes also about the professional and academic goals. Typically, First-generation college students do not have the opportunity to voice their career and educational goals, and this provides them with a unique opportunity.

\section{Challenges}

One of the biggest challenges faced when directing programs such as ACCESS and McNair is the steep learning curve during the initial implementation stage. At a small-to-medium-sized institution, it is easier to get to know the key players on a personal level who can provide logistical support. For both programs, one must focus on numerous details that do not directly connect to the students' academic success. These can range from housing and food for summer programs to identifying the correct paperwork in order to disburse stipends. For a program such as McNair, which has federal funds that support the infrastructure of the program, one can hire staff to take care of such details. For programs such as ACCESS, where the funding is comparatively small, the director must personally make connections with all the appropriate people from various divisions on campus. Because of the relatively small size of the university, many of those people work in concert with one another and are often willing to go the extra distance to make things run smoothly. Without such personal connections, navigating through bureaucratic red tape would be much more challenging.

\section{Success in the ACCESS Program}

Overall, ACCESS has had 164 student participants since its start in 2009, with roughly equal numbers of males and females; $27 \%$ identify as African-American, 7\% Asian, 62\% Latino, and 4\% White.

ACCESS runs on a yearly budget of about $\$ 80,000$, where about $39 \%$ goes directly to support participant costs like food, housing, field trips, transportation, textbooks, etc. The ultimate measure of the effectiveness of the ACCESS Program will be the long-term success of the students. We can measure their success in terms of grade point average, retention, and ultimately career paths after college. For the first four cohorts (2009, $2010,2011,2012)$, the overall 6-year graduation rate from LMU for students with any degree is $88.9 \%(64 / 72$ students). The pre- and post-summer data show that ACCESS participants feel that the program helps them to get acclimated to LMU and helps nurture a positive sense of belonging and community. ACCESS participants have also had success after their time at LMU. Many have gone on to STEM careers and graduate school. Data from participants in the 2009-2012 cohorts show that at least 18 of the participants went on to graduate or medical school or have begun careers in STEM fields.

\section{Success in the LMU McNair Program}

The LMU McNair Scholars Program provides the structure necessary to sustain a support system for a qualified group of first generation, low-income, and underrepresented undergraduate students. Each academic year, we identify and address the higher education needs of 26 first generation, low-income and underrepresented undergraduates who are interested in attending graduate school to earn a doctoral degree. This target population is recruited from the College of Science and Engineering, which has 100\% STEM majors, and students majoring in Economics, Political Science, Psychology, and Sociology in the College of Liberal Arts. A deliberate effort is made to ensure that the McNair Scholars are a gender-balanced group so as to also address the challenge of women underrepresentation in STEM. A significant component of the program is its emphasis on undergraduate research that allows students to collaborate with faculty and become involved in ongoing undergraduate research. It exposes them to an environment in which they can be supported as they experiment in STEM and perhaps struggle without negative repercussions and which provides them opportunities to write up and present research findings. Other components of the program include providing GRE preparation courses, educating students about academic/professional supply and demand trends in STEM fields, and establishing bridges for students transitioning from college to graduate school to STEM careers. The table below presents details about the program since its start in 2012 to 2017. 
Table 1.

LMU McNair Program Data

\begin{tabular}{ll} 
Students accepted into the McNair program $(2012-2017)$ & 86 \\
Scholars completed the program (until spring 2017) & 61 \\
Scholars currently enrolled in the program (AY 2017 - 2018) & 25 \\
Average cumulative GPA of scholars graduated (until 2016) & 3.5 \\
LMU McNair Scholars who went to graduate school between $(2012-2017)$ & 34 \\
Conferences where LMU McNair scholars presented their research $(2012-2017)$ & 30 \\
Conference research presentations by LMU juniors and seniors (AY 2016-2017) & 81 \\
\hline
\end{tabular}

Notes: $\mathrm{n}=86$

The LMU McNair program continues to achieve the overarching goal of McNair programs, which is, increasing graduate degree awards for students from underrepresented segments of society. Since 2012, 34 of the 86 LMU McNair scholars have enrolled in graduate programs in the fields of math, engineering, life sciences, and social science and have also enrolled in medical school, $\mathrm{MD} / \mathrm{PhD}$ programs and JD programs. Students attend graduate programs at national and international institutions, such as, MIT, Tufts, UC Berkeley, Claremont Graduate University, University of Southern California, Emory, École Polytechnique Federale de Lausanne (EPFL) and London School of Economics, just to name a few. In 2017, the first LMU McNair program alum received her $\mathrm{PHD}$ in the biological sciences.

Over the past 5 summers (2013, 2014, 2015, 2016, 2017), 66 McNair scholars have participated in LMU's summer research program. In addition, 13 McNair scholars have participated in summer research opportunities away from the LMU campus at the following universities:

- Arizona State University

- Carnegie Mellon

- Duke University

- Harvard University

- Louisiana State

- Ohio State

- UC Berkeley

- UCLA

- University of Connecticut

- University of Iowa

- USC

- University of Wisconsin at Madison

- Wake Forest School of Medicine

Scholars have also participated in summer internship opportunities at several sites, such as, Space X, Moog Inc., and Northrop Grumman. LMU McNair has sent student scholars to over 30 different conferences to present their research and expand their discipline specific network. For 2016 -2017 academic year, over 81 research presentations were given by the junior and senior cohorts. LMU McNair scholars have received awards and recognition including one Amgen scholar, one NCAA Graduate School scholarship, and two GEM Fellowships. 


\section{Conclusion}

We attribute much of the success of both ACCESS and McNair at LMU to the dedication and support received from faculty, staff, and administration at LMU. Studies have shown that support systems that include many of the components in both ACCESS and LMU McNair, such as student community-building efforts, undergraduate research programs, academic enrichment programs, tutoring and mentoring are essential in broadening URM participation in STEM (Rodriguez et al., 2012). While both programs have had success, directors still have additional goals they would like to achieve. As the number of applicants increase in both programs, the project team is looking for ways the programs can be expanded to include more student participants. The ACCESS leadership team has applied for funding from the NSF to provide scholarships to ACCESS students over the next 5 years. The LMU McNair program was recently approved for another five-year funding cycle. Future plans for the McNair program involve incorporating new initiatives and methodologies that would further increase the number and proportion of underrepresented students prepared for graduate study in STEM.

Overall, the contributions made by both programs have greatly impacted the Seaver College of Science and Engineering at LMU. While both programs have individualized, peer and community mentoring at both levels, the data mentioned above shows that these various mentoring structures have contributed to success of its participants. Moreover, the mere existence of such programs contributes to a culture that engages in dialog about how best to support a diverse student body. Synergistic relationships between ACCESS, McNair and other on-campus programs with similar missions have evolved over the past 5-10 years, and this has led to new individuals becoming involved in the support of our cause.

\section{Funding Sources}

The ACCESS program is funded by private donors and NSF-DUE grant 1153820. The LMU McNair Scholars program is a federal TRIO program funded by the U.S. Department of Education grant P217A120197.

\section{References}

Anderman, L. H., \& Freeman, T. (2004). Students' sense of belonging in school. In P. R. Pintrich \& M. L. Maehr (Eds.), Motivating students, improving schools. Advances in motivation and achievement, (Vol 13, pp. 27-63). Oxford, UK: Elsevier.

Chang, M. J., Denson, N., Saenz, V., \& Misa, K. (2006). The educational benefits of sustaining cross-racial interaction among undergraduates. The Journal of Higher Education, 77(3), 430-455.

Chubin, D., DePass, A. L., \& Blockus, L. (2009). Understanding Interventions That Broaden Participation in Research Careers (Vol III), Summary of a Conference. Bethesda, MD: American Association for the Advancement of Science.

Herzig, A. (2004). Becoming mathematicians: Women and students of color choosing and leaving doctoral mathematics. Review of Educational Research, 74(2), 171- 214.

Huang, G., Taddese, N., \& Walter, E. (2000). Entry and persistence of women and minorities in college science and engineering education. (NCES Publication No. 2000-601). Washington, DC: National Center for Education Statistics.

Ianni, F. A. J. \& Orr, T. M. (1996). Dropping out. In J. Graber, A, J. Brooks-Gunn, \& A. Peterson: Transitions through adolescence: Interpersonal Domains and Context. J. Graber, A, J. Brooks-Gunn and A. Peterson (pp. 285-321). Mahwah, NJ: Lawrence Erlbaum Associates.

Morisano, D., Hirsh, J. B., Peterson, J. B, Pihl, R.O, \& Shore, B. M. (2010). Setting, elaborating, and reflecting on personal goals improves academic performance. Journal of Applied Psychology, 95(2), 255-64.

NAP (2011). Expanding Underrepresented Minority Participation: America's Science and Technology Talent at the Crossroads, by the National Research Council. Washington, DC: The National Academies Press. 
Nora, A. (2001). The depiction of significant others in Tinto's "Rites of Passage:" A reconceptualization of the influence of family and community in the persistence process. Journal of College Student Retention: Research, Theory \& Practice, 3(1), 41-56.

Rodriguez, C., R. Kirshstein, L. Amos, W. Jones, L. Espinoa, \& Watnick, D. (2012). Broadening Participation in STEM: A Call to Action. Washington, DC: American Institutes for Research.

Steele, C. M., \& Aronson, J. (1998), Stereotype threat and the test performance of academically successful African Americans. Journal of Personality and Social Psychology, 69(5), 797- 811.

Tinto, V. (1997). Colleges as communities: Exploring the education character of student persistence. Journal of Higher Education, 68(6), 599-623.

White House. (2010). Educate to Innovate. Retrieved 2011, from http://www.whitehouse.gov/issues/education/ educate-innovate. 